\title{
ANISOTROPIC NON-SILICIOUS CRYSTALLINE INCLUSIONS IN A DYSGERMINOMA OF TUBERCULOID APPEARANCE
}

\author{
BY \\ R. ERIC POTTS \\ From the Pathology Laboratory, Kilmarnock Infirmary, Ayrshire
}

(RECEIVED FOR PUBLICATION DECEMBER 17, 1951)

It is widely recognized that in lesions involving the ovary and Fallopian tube the histological appearances of dysgerminoma on the one hand, and talc granuloma on the other, may in some instances resemble those of tuberculosis. Conversely, the lesions of tuberculous salpingitis may also, in certain cases, closely mimic those of tubal carcinoma or tubal talc granuloma. In these circumstances crystals in lesions of the Fallopian tube assume diagnostic significance. Roberts (1947) called attention to the lesion of tubal talc granuloma and demonstrated the silicious nature of the doubly refractile crystals therein, and Potts (1951) recorded the occurrence of non-silicious anisotropic crystals in tuberculous salpingitis. It is the purpose of the present communication to record the finding of birefringent, intracellular, non-silicious crystals in a dysgerminoma of tuberculoid appearance involving the Fallopian tube and to discuss the diagnostic implications of this observation.

\section{Case Report}

M.S., an unmarried woman of 23 years, was admitted to hospital on August 18, 1950, complaining of rightsided abdominal pain of several weeks' duration. She gave no history of previous surgical intervention. A hard mass, probably ovarian, was palpable in the right lower abdomen and at operation the mass was confirmed as a tumour of the right ovary. The right Fallopian tube was adherent to the tumour which apparently involved it, and there was a further mass behind the mesentery in the retroperitoneal tissues. The left ovary and tube appeared healthy.

\section{Pathology}

The specimen was an ovoid mass of $9 \mathrm{~cm}$. diameter replacing the right ovary and continuous with the related Fallopian tube of which $5 \mathrm{~cm}$. was present. The ovarian tumour had a smooth surface and was bounded by a tough capsule, and in slices it was firm and grey with numerous small irregular yellow areas. The distal half of the portion of Fallopian tube was enlarged up to $2 \mathrm{~cm}$. maximum diameter and on section showed a small eccentric lumen and much thickening of the wall and adjacent broad ligament of a similar appearance to the ovarian tumour.

Histologically, the ovarian tumour and its tubal extension presented two quite dissimilar pictures. In the lesser part of the considerable tissue sampled the neoplasm presented the typical appearance of a dysgerminoma (Fig. 1). The neoplastic cells were large, round, and uniform, and each had a large

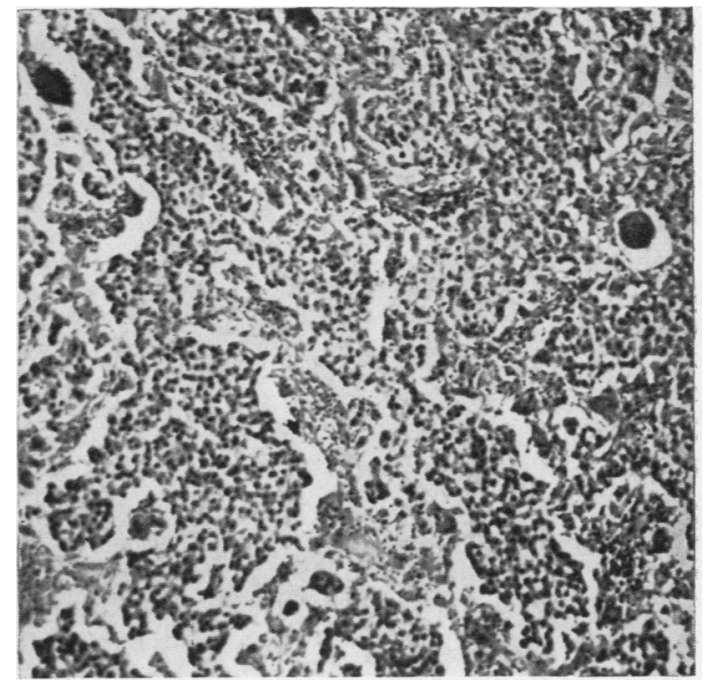

FIG. 1.-Dysgerminoma of typical pattern. (Haematoxylin and eosin, $\times 35$.)

vesicular nucleus and abundant, clear, and translucent, or even slightly basophilic, cytoplasm. The nucleus was rich in chromatin in a coarsely granular distribution and featured one, or occasionally more than one, prominent nucleolus. At a magnification of 480 diameters, mitotic figures averaged 2.5 per field. The cells were supported by a delicate fibrous stroma and arranged in characteristic 


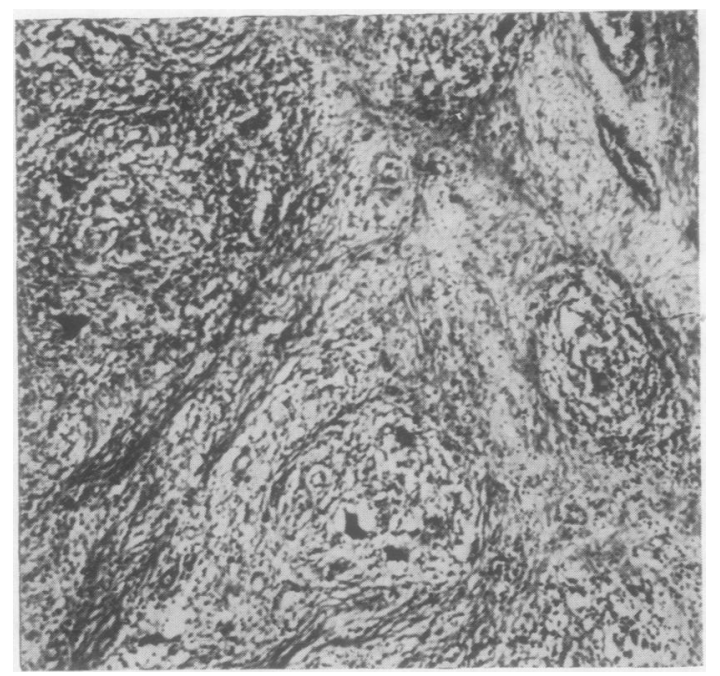

FIG. 2.-Dysgerminoma of follicular pattern in which many of the follicles contain one or more darkly staining giant cells. (Haematoxylin and eosin, $\times 35$.)

alveolar fashion, while the bands of fibrous tissue presented not only the usual lymphocytic infiltration but also numerous plasma cells.

In the major part of the material, however, there was at low magnification a superficial resemblance to non-caseous tubercle in the stage of early fibrous healing (Fig. 2). Follicles or islets of palely staining cells of irregular outline were circumscribed by abundant fibrous tissue infiltrated, in lesser or greater degree, by lymphocytes. Many of the follicles contained one, or more than one, multinucleate giant cell of the order of 100 microns and occasionally much larger. At higher magnification the epithelioid cells forming these follicles were not of uniform tyre. Some appeared as poorly outlined, interwoven cells with palely eosinophilic or clear cytoplasm and a small vesicular nucleus similar to the epithelioid cells found in the "soft" tubercle; others were frankly neoplastic cells readily identifiable by their much larger and coarser nuclei and prominent nucleoli, while in many the cell nuclei showed varying degrees of karyolysis, so that it was not possible to classify them with certainty as neoplastic or reactive. Of the multinucleate giant cells which formed a prominent feature of many of the follicles, a few showed the peripheral nuclear arrangement of the Langhans type of cell, but the majority presented a widely scattered nuclear distribution. The multiple nuclei, each about one third of the size of the nucleus of the average tumour cell, were oval in shape and poor in chromatin, while the cytoplasm was deeply eosinophilic and frequently vacuolated. Other multinucleate cells, of smaller size and having fewer, larger, and more deeply stained nuclei, were clearly symplastic tumour giant cells, and again some of the multinucleate cells could not be classified. At the margin of the follicles the peripheral fibroblastic reaction rapidly gave place to the abundant collagenous tissue which separated the individual follicles. Occasionally small foci consisting of one or two foreign-body giant cells and a few macrophages, lymphocytes, and plasma cells were encountered in the stroma far removed from recognizable neoplastic cells (Fig. 3). Not only were lymphocytes present in the peripheral fibrous boundary zone of the follicles, but plasma cells were also numerous and in parts predominant, while a proportion of cells were
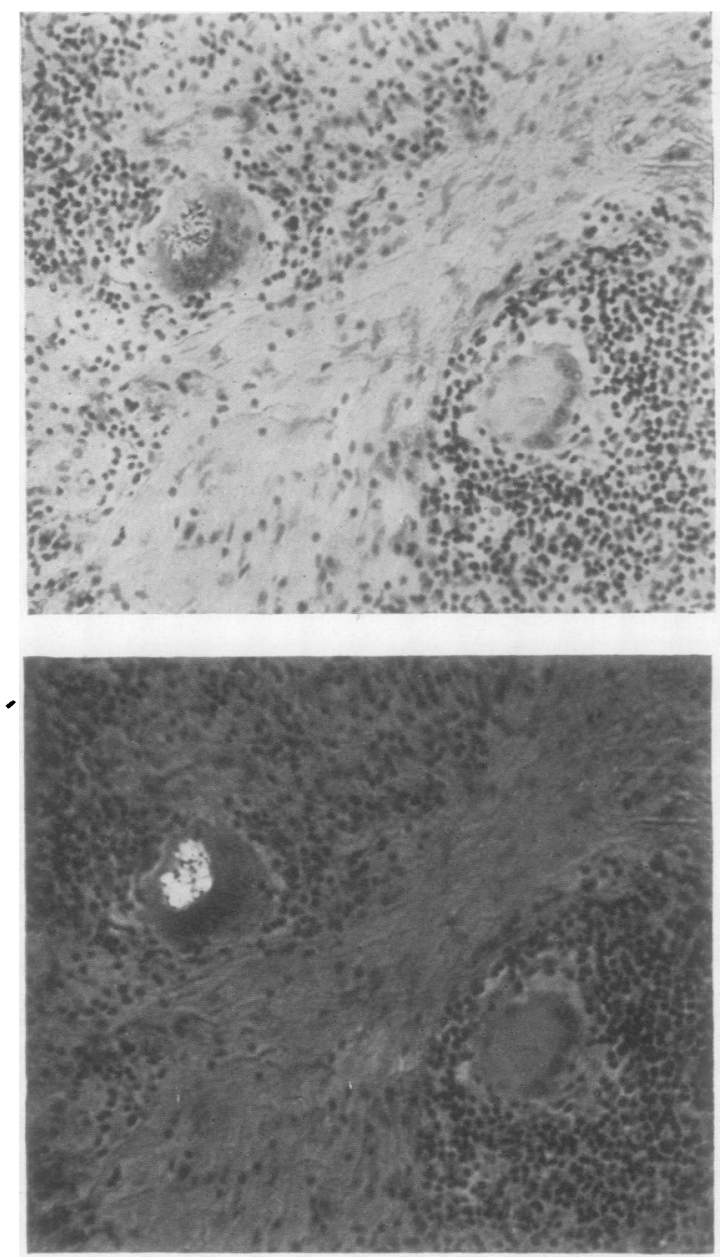

Fig. 3.-Two large multinucleate giant cells photographed by direct illumination and through crossed polaroid screens. The foreign body type of cell contains an aggregation of birefringent crystals. bo inclusions are present in the Langhans cell. (Haematoxylin
No and eosin, $x$ 170.) 
identified as large mononuclears by their abundant cytoplasm and nuclei similar to those of the foreignbody giant cells. Crystalline inclusions were present in many, but by no means all, of the multinucleate giant cells (Fig. 3) and were also found occasionally in degenerate tumour cells or macrophages, but since the nuclear staining of these latter cells was commonly absent they could not be classified. The crystals appeared translucent or pale yellow, were inconspicuous by transmitted illumination, but were strongly birefringent. They were variable in size up to 50 microns, and the larger examples were considered as aggregations of smaller crystals since different parts of the same mass "blacked out" at different degrees of rotation of the slide between crossed polaroid screens. They were always readily soluble in dilute mineral acids within 30 minutes; indeed most dissolved within five minutes. While usually occurring alone, a few of the crystals were intimately associated with basophilic laminated bodies (Fig. 4) of the order of 10 to 50 microns or even larger, while these latter also occurred sometimes independently within giant cells or extracellularly in relation to such cells. They appeared morphologically similar to the bodies encountered from time to time in the lesions of tuberculosis and sarcoidosis, and, like them, gave positive results with stains for iron.

Sections taken from the proximal portion of the specimen of Fallopian tube were without evidence of tumour invasion or of chronic inflammatory changes, and numerous sections from the distal

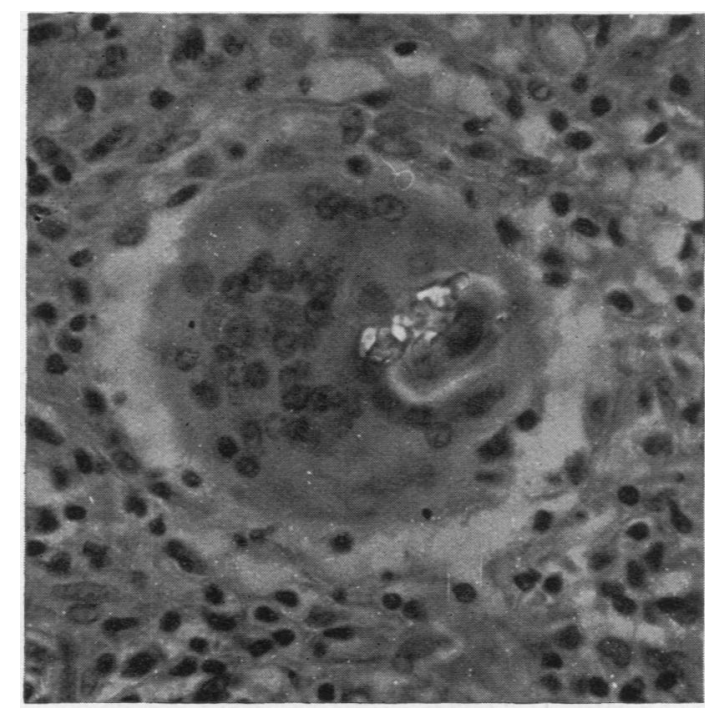

Fig. 4.-A large multinucleate giant cell of foreign body type photographed through partially crossed polaroid screens to show the graphed through partially crossed polaroid screens to show the
intimate association of birefringent crystals with an isotropic intimate association of birefringent crystals with an isotropic
concentric laminated body. (Haematoxylin and eosin, $\times 450$.) $\mathbf{R}$ portion, in which a tuberculoid appearance was apparent, showed no acid-fast organisms. Glycogen was easily demonstrable by the periodic acid-Schiff technique (with saliva control) in both the tuberculoid and the typical areas of the tumour. Frozen sections stained by Sudan black showed diffuse dark grey staining of the cytoplasm of the majority of the multinucleate giant cells, but fatty material in the tumour cells was not demonstrated.

\section{Discussion}

The Tuberculoid Type of Lesion.-In a paper devoted to the subject of dysgerminoma and tuberculosis Schiller (1934) concluded that the tuberclelike follicular lesions encountered occasionally in such tumours were not of tuberculous aetiology. In a review of the literature on the subject he classified as tuberculoid dysgerminoma five cases previously reported by Kermauner as coexisting granulosa cell tumour and tuberculosis, and several cases previously reported by various other authors as coexisting dysgerminoma and tuberculosis. In his Case 7 , which bore a very close resemblance to tuberculosis, not only were suitably stained sections negative for tūbercle bacilli but animal inoculation of the tissue and the tuberculin reaction of the patient were also negative. He, therefore, suggested that the tissue reaction was produced by fatty substances derived from the degeneration of the tumour cells. In contrast to this view that the epithelioid cells and multinucleate giant cells were a product of the stromal reaction, Novak and Gray (1938) regarded them as degenerate neoplastic cells, the giant cells in their opinion being symplastic in nature. Föderl (1938) found pseudo-tubercles in tumour thrombi lying within the lumina of small vessels, and, as no stromal elements were found, he assumed an origin either from tumour cells or endothelial cells, while he also pointed out that dysgerminoma cells were themselves mesenchymal derivatives. In the five cases of dysgerminoma reported by Sailer (1940), two presented a few pseudotubercles, but the feature was not prominent and he expressed no opinion regarding their origin. More recently, however, Heller (1943) in a study of two cases of tuberculoid dysgerminoma reached a conclusion similar to that of Schiller, while Potter (1946) in reporting a single case referred to the frequent presence of giant cells resembling Langhans cells, but gave no views as to their development. In the case presented here, the resemblance to tuberculosis was comparatively superficial as detailed study of the follicles showed significant differences from the follicular lesions of tuberculosis. 
Of these the most striking was the vascularity; small capillary vessels were frequent within the central mass of pale epithelioid cells. A further differential point was that lymphocytes were not confined to the periphery of the follicles but were seen at focal areas within the epithelioid cell core or even diffusely scattered throughout. The cytological classification of the epithelioid cells was, however, a matter of greater difficulty, and the two widely differing views regarding the origin of these cells and the multinucleate giant cells were readily appreciated. The tuberculoid appearance was confined to those areas where degenerative changes in the tumour cells were prominent, and in the process of degeneration the cytoplasm of such cells becomes eosinophilic. Furthermore, the nuclei of the neoplastic cells showed varying degrees of karyolysis and, while generally large, exhibited the range in size usual to nuclei in poorly differentiated neoplastic tissue. There were, too, some small multinucleate protoplasmic masses clearly formed by fusion of three or four degenerate tumour cells. On the other hand, the frequent occurrence of deeply eosinophilic giant cells of the order of 100 microns containing upwards of 10 , and occasionally more than 30 small uniform nuclei, left little doubt that these were true foreign-body giant cells and as such were to be regarded as derived from histiocytes. For the reasons given above it was not possible to identify with certainty macrophages within the islets, but at the periphery of the follicles such cells could be recognized in the fibroblastic tissue along with lymphocytes and plasma cells. Plasma cells were seen not only in the fibrous stroma in the tuberculoid parts of the tumour, but also in the supporting trabeculae of the more histologically typical areas of the neoplasm. These cells were also a feature of the lesion in the cases reported by Heller (1943) and he regarded them as supporting the hypothesis of an inflammatory or stromal origin of the epithelioid cells of the follicles. This argument appears to ignore the frequent occurrence of plasma cells in the supporting stroma of diverse neoplasms. Heller also commented on the presence of eosinophils, but these cells were not identinied in the present material although occasional plasma cells presented eosinophilic Russell bodies. In my own view the epithelioid cells of the follicles are to be interpreted in part as degenerating tumour cells and in part as macrophages engaged in the scavenging thereof, while the multinucleate giant cells are similarly of neoplastic and reactive origin, that is, of both symplastic and foreign body type. A tuberculoid appearance in neoplasms is not confined to dysgerminoma: such a histological picture has been reported in neurocytoma (Hartz and van der Sar, 1945) and in granulosa cell carcinoma (Schattenberg and Harris, 1946). In the former case the authors concluded that " it may be safely assumed that the epithelioid cells were of mesenchymal origin," while in the latter case the theory of Schiller was regarded as the probable explanation, although no frozen sections were made to confirm the presence of fatty material. Schiller (1934) originally postulated that the tuberculoid tissue reaction in dysgerminoma was produced by fatty substances resulting from degeneration of the tumour cells, and in a later communication he (Schiller, 1936) noted that " a fat stain will reveal abundant lipoid," but he did not specify either the stain used or the site of the lipoid. Greenblatt and Pund (1938), however, were only able to find occasional macrophages and giant cells containing sudanophilic material. This latter finding was my own experience in material from this case, although it must be noted that the tissue was stored in formalin for several months before frozen sections were cut. While neutral fats are unaffected by such treatment, phospholipines form fine emulsions in water and gradually disappear from tissues stored in formalin. On the other hand, it is worthy of note that glycogen was readily demonstrable, though not abundant, in the tumour cells-yet another contradiction of the still frequently repeated fallacy that alcoholic fixation is necessary for the demonstration of this substance. Greenblatt, Greenhill, and Brown (1939) investigated the lipid content of various ovarian neoplasms, and stated that fatty material might be found in such tumours, due either to degenerative changes or to tissue metabolism (hormone storage); in dysgerminoma the fat was considered as degenerative in origin. The present case provides no evidence for or against the presence of lipid material in the degenerate areas of the tumour, since any such lipid might be expected to be phospholipine rather than neutral fat and as such would be removed by storage in an aqueous fixative.

Crystals. - So far as I am aware, the presence of birefringent crystals in a dysgerminoma has not hitherto been reported. The occurrence of such crystals in a tumour of tuberculoid histological appearance involving the Fallopian tube is noteworthy in that anisotropic crystalline inclusions are of some diagnostic significance in lesions involving a Fallopian tube and ovary. Roberts (1947) in a paper devoted to tubal silicious granuloma reported five such cases although only one was proved by micro-incineration. At the same time he commented on the similarity of the histological picture to that of tuberculous salpingitis and referred to the possibility of reaching this erroneous diagnosis in such lesions. On the other hand, Potts (1951) 
called attention to the presence of acid-soluble, birefringent crystals in the giant cells of tuberculous salpingitis and remarked upon the converse possibility of wrongly labelling such lesions as talc granuloma. Diagnostic errors have in the past arisen in the interpretation of the tuberculoid type of dysgerminoma. While this pitfall is now widely recognized, there remains the possibility of misinterpreting a lesion showing anisotropic crystals within the giant cells for coexisting dysgerminoma and silicious granuloma. Illusory support for such a diagnosis might well be provided by the ubiquitous appendicectomy scar.

In the present case all the doubly refractile crystals were readily soluble in dilute mineral acids, and sections presenting such crystalline inclusions were, after 30 minutes' immersion in N/1 hydrochloric acid, consistently free from anisotropic material. It is not within the scope of this communication to discuss the chemical nature of these crystals. This will be the subject of a separate paper. It may, however, be said that the crystalline inclusions and those which are to be found in many cases of tuberculous salpingitis have so many properties in common, both chemical and physical, as to leave no doubt that they are identical.

\section{Summary}

A case is presented of an ovarian dysgerminoma involving the related Fallopian tube in which the histological appearance of the greater part of the tumour was tuberculoid.

The origin of the epithelioid cells and multinucleate giant cells is considered and the relevant literature is briefly reviewed.

Attention is drawn to the presence of nonsilicious anisotropic crystals within some of the multinucleate giant cells and the diagnostic implications of this finding are discussed.

I am indebted to Dr. W. B. Davis for helpful suggestions in the preparation of this paper and to Mr. H. Gray for the photomicrographs.

REFERENCES
Föderl, V. (1938). Arch. Gynäk., 165, 392.

Greenblatt, R. B., Greenhill, J. P., and Brown, W. R. (1939). Amer. J. Obstet. Gynec., $37,929$. and Pund, E. R. (1938). Ibid., 35, 667.

Hartz, P. H., and van der Sar, A. (1945). Amer. J. clin. Path., 15, 473. Heller, E. L. (1943). Arch. Path., Chicago, 35, 674.

Novak, E., and Gray, L. A. (1938). Amer. J. Obstet. Gynec., 35, 925.

Novak, E., and Gray, L. A. (1938)., Amer.

Potter, E. B. (1946). Amer. J. Path., 22, 551.

Roberts, G. B. S. (1947). Brit. J. Surg., 34, 417.

Sailer, S. (1940). Amer. J. Cancer, 38, 473,

Schattenberg, H. J., and Harris, W. H. (1946). Amer. J. Path., $22,539$.

Schiller, W. (1934) Arch. Gynik . 156, 513.

(1936). J. Obstet. Gynaec. Brit. Emp., 43, 1135. 